\title{
Carlos Alvarado-Larroucau, Écritures palestiniennes francophones. Quête d'identité en espace néocolonial
}

\section{Veronica Amadessi}

\section{(2) OpenEdition}

1 Journals

\section{Édition électronique}

URL : http://journals.openedition.org/studifrancesi/7049

DOI : 10.4000/studifrancesi.7049

ISSN : 2427-5856

Éditeur

Rosenberg \& Sellier

\section{Édition imprimée}

Date de publication : 1 septembre 2010

Pagination : 413-414

ISSN : 0039-2944

\section{Référence électronique}

Veronica Amadessi, « Carlos Alvarado-Larroucau, Écritures palestiniennes francophones. Quête d'identité en espace néocolonial », Studi Francesi [En ligne], 161 (LIV | II) | 2010, mis en ligne le 30 novembre 2015, consulté le 08 janvier 2021. URL : http://journals.openedition.org/studifrancesi/7049 ; DOI : https:// doi.org/10.4000/studifrancesi.7049

Ce document a été généré automatiquement le 8 janvier 2021.

\section{(c) $($ ) $\odot$}

Studi Francesi è distribuita con Licenza Creative Commons Attribuzione - Non commerciale - Non opere derivate 4.0 Internazionale. 


\title{
Carlos Alvarado-Larroucau, Écritures palestiniennes francophones. Quête d'identité en espace néocolonial
}

\author{
Veronica Amadessi
}

\section{RÉFÉRENCE}

CARLOS ALVARADO-LARROUCAU, Écritures palestiniennes francophones. Quête d'identité en espace néocolonial, Paris, L'Harmattan, 2009, pp. 173.

1 Ce volume est un des premiers travaux de recherche consacrés à la littérature palestinienne contemporaine de langue française et a pour but de tracer un panorama de cette littérature, à travers l'analyse de genres et d'auteurs. Cette production se définit, d'après Alvarado-Larroucau, comme appartenant à un «néocolonialisme» sui generis, lié à l'étrange situation historique de la Palestine contemporaine, notamment au fait que les nouvelles «colonies» juives s'installant dans les territoires ne sont pas l'expression d'une puissance coloniale qui provient de l'extérieur mais de l'intérieur même du pays. Bien que l'auteur évite tout jugement de valeur et toute prise de position, il est indéniable que la scène politique occupe une place importante au sein de cette production littéraire, qui est assez récente (les textes analysés sont tous écrits aux alentours de l'année 2000 ou peu avant). Les œuvres du corpus embrassent tous les genres littéraires et représentent un échantillon des travaux des écrivains palestiniens francophones, peu nombreux et, par conséquent, peu connus.

Cette étude se concentre surtout sur la notion d'identité, sujet complexe abordé dans l'introduction, qui souligne que ce mot, comme l'a expliqué Paul Ricœur en 1988, possède deux acceptions, à la fois celle de «mêmeté» et celle d'«ipséité». De plus, le paradoxe du concept même est mis en cause, à savoir que l'identité se construit sur un double mouvement de similitude et de différence: ces deux éléments sont donc pris en compte lors de l'analyse des textes. Il est nécessaire de souligner que cette critique 
textuelle considère à la fois l'aspect textuel proprement dit et aussi une «étude externe» du texte, où la sociologie et la psychanalyse jouent un rôle fondamental. Autrement dit, les discours hétérogènes contenus dans le texte, qui ont le pouvoir de mettre ce dernier en relation au «hors-texte», sont analysés sous des perspectives différentes, l'objectif étant de s'intéresser à la «sociologie du texte» et à la question de l'identité traduite par la fiction.

3 Le volume se compose de trois parties organisées en chapitres: la première définit surtout les outils indispensables à la compréhension du sujet et à l'analyse textuelle. Il est question d'établir d'abord l'identité $d u$ texte, en analysant sa forme et ses titres; la littérature palestinienne se créant dans un état d'urgence, le récit y occupe une place importante, et l'analyse de l'auteur vise à déterminer si ces textes appartiennent à une énonciation discursive ou à une énonciation historique. Après avoir cerné l'identité $d u$ texte, la deuxième partie change de focalisation, pour se concentrer sur la question de l'identité dans le texte. Les deux aspects ne sauraient être séparés car ils sont complémentaires. C'est pourquoi, après une mise en contexte des œuvres, l'étude se concentre sur les façons dont les écrivains palestiniens développent ou construisent une identité (individuelle ou collective) à l'intérieur du texte. Les auteurs sont mis en relation entre eux pour faire ressortir les différences et les éventuelles affinités qui existent entre leurs textes.

4 La dernière section du volume approfondit la thématique identitaire qui se manifeste dans les ouvrages qui font l'objet de cette réflexion, et en isole quelques aspects. L'accent est mis, notamment, sur l'identité féminine, très présente dans les œuvres étudiées, et sur le concept de négation de l'identité palestinienne que les auteurs s'approprient. Il ressort, en particulier, que la voix des femmes, militantes de la cause palestinienne à travers le langage, joue un rôle capital dans cette production littéraire, puisque l'écriture se renouvelle en s'emparant du langage contemporain et en choisissant le français en tant que langue d'écriture neutre. L'identification physique avec la cause historique semble être un autre élément qui caractérise les ouvrages des femmes palestiniennes, ainsi que la condition d'aliénation et d'étrangeté.

Ce travail, qui signale donc l'importance de la langue française et de son enseignement dans la région, contient des analyses nouvelles qui ouvrent des perspectives intéressantes, car il met en relation plusieurs disciplines faisant partie des sciences humaines comme la littérature. Alvarado-Larroucau a le mérite d'aborder une littérature d'expression française encore peu connue et étudiée, et d'offrir l'aperçu d'une production assez récente et actuelle pour ses contenus. L'intérêt de cet ouvrage, en tout cas, est sans doute d'offrir une étude pointue et détaillée de quelques textes fondamentaux de la littérature francophone en Palestine, en passant de l'analyse générale à l'analyse détaillée des deux dernières parties. Reste à espérer que ce travail contribuera à diffuser la publication d'auteurs encore peu connus en Europe comme Ibrahim Souss, Raymonda Hawa-Tawil ou Elias Sanbar, et que cette étude débouche sur des travaux critiques ultérieurs. 